\section{Extradural hematoma in Plasmodium vivax malaria: Are we alert to detect?}

Sir,

Malaria continues to be an important parasitic disease in tropics and contributes to morbidity and mortality..$^{[1]}$ We report a case of Plasmodium vivax infection who presented with features of spontaneous extradural bleed in order to create an awareness of this unusual entity among practitioners.

A 22-years-old male lorry driver was referred from a private hospital to our emergency department (ED) for altered sensorium, while he was on treatment for 4 days for smear positive vivax malaria. He recently had a trip to northern India in the lorry. There was no history of trauma, fall from height, seizure, bleeding diathesis, substance abuse, or intake of any herbal preparations. Prior to referral he was given chloroquine, paracetamol, domperidone orally, and intravenous fluids for 3 days. However, fever persisted even after a course of oral chloroquine as per WHO recommendation. On examination in ED, he was drowsy, disoriented with Glasgow Coma Scale of 9 (E2, $\mathrm{M} 5$, and V2), febrile $\left(102.5^{\circ} \mathrm{F}\right)$, dehydrated, pale, and icteric. There were no other bleeding manifestations. He was hemodynamically stable and maintaining adequate saturation in room air. He had diffuse abdominal tenderness with hepatosplenomegaly. His pupils were unequal with sluggish reaction to light and planters were bilaterally extensor. There was no neck rigidity. His investigations revealed hemoglobin of $6.0 \mathrm{gm} / \mathrm{dl}$ (normal: 12.5-14.5), platelet count of $45,000 /$ cumm $(140,000$ $400,000)$, serum creatinine of $1.8 \mathrm{mg} / \mathrm{dl}$, total bilirubin $9.6 \mathrm{mg} / \mathrm{dl}(0.4-1)$, International normalized ratio (INR) of 1.12 , and activated partial thromboplastin time (APTT) of $30 \mathrm{~s}$ (24-32). His remaining parameters were within normal limits. His HIV status was negative. Peripheral blood smear was positive for Plasmodium vivax gametocytes and ring stages with marked parasitaemia and rapid card test was done to rule out undetected mixed infection, which is based on detecting specific Plasmodium LDH antigen by using monoclonal antibody directed against iso-forms of the enzyme. Noncontrast computed tomography of the cranium demonstrated left side extradural hematoma [Figure 1]. He was started on intravenous artesunate $2.4 \mathrm{mg} / \mathrm{kg}$ at the time of admission, then at 12 and $24 \mathrm{~h}$, and then, once a day for 5 days. In view of his deteriorating neurological status, he underwent prompt surgical decompression and $50 \mathrm{ml}$ of dark red blood clots were evacuated. As he had high parasitic index, partial exchange transfusion $(1350 \mathrm{ml})$ was carried out which reduced the parasitaemia. He had a favorable outcome, with remarkable clinical improvement in the immediate postoperative period. We did not start oral artesunate tablets because it also contains mefloquine, which can precipitate neuropsychiatric complications. The repeat peripheral smear at the time of discharge was free of malarial parasite and he was discharged on primaquine $15 \mathrm{mg} /$ day for 14 days after screening for G6PD deficiency.

Plasmodium vivax infection though considered to be benign and self-limiting disease, in recent past it has produced severe and complicated malaria. ${ }^{[2]}$ The altered sensorium in a malarial patient is often mistaken for cerebral malaria. ${ }^{[3]}$

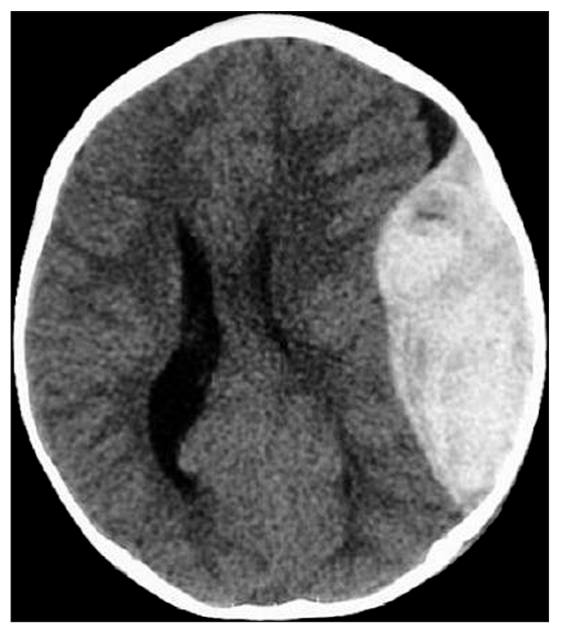

Figure 1: Noncontrast axial cranial CT revealing left temporoparietal acute extradural hematoma 
The occurrence of intracranial hematoma is rare in malaria. Earlier extradural bleed and subdural hematoma were demonstrated in falciparum malaria. ${ }^{[4-7]}$ It appears that this patient developed spontaneous extradural bleed in the absence of other demonstrable causes for bleeding. Extradural bleed in this patient may be due to the rupture of a small vessel and/or cerebral venules plugged by parasitized erythrocytes coupled with thrombocytopenia. The microrheologic research had clearly demonstrated that P. vivax infection enhances the aggregation, erythrocyte clumping, and reduces deformability affecting the microcirculation. ${ }^{[8]}$ When infected erythrocyte sequestrates, there is local production of lactate due to impaired tissue perfusion. Thus, the cellular hypoxia increases the production of serum tumor necrosis factor- $\alpha$ (TNF- $\alpha$ ), a potential immunogenetic marker, and vary with severity of disease. TNF induces profound alterations in endothelial integrity. Also, complex interaction occurs between platelet and parasitized red blood cells leading to vascular injury. All these might have contributed to extradural hematoma in this case. Polymerase chain reaction could not be done due technical limitations. The lesson learnt is that development of an altered sensorium in an established case of malaria while on specific therapy should not be mistaken only as cerebral malaria since it is a diagnosis of exclusion and treated without reconsideration or confirmation by additional entities and investigations will increase the mortality and morbidity. The failure to clear parasitaemia is an indication that the treatment is no longer useful and should be changed.

S. SenthilKumaran, N Balamurugan ${ }^{1}$, P Suresh, P Thirumalaikolundusubramanian ${ }^{2}$

Departments of Emergency, Critical Care Medicine, ${ }^{1}$ Neurosciences, Sri Gokulam hospital and Research Institute, Salem, ${ }^{2}$ Chennai Medical College Hospital and Research Centre, Irungalur, Trichy, India

Address for correspondence: Dr. S. SenthilKumaran, Department of Emergency and Critical Care Medicine, Sri Gokulam Hospital and Research Institute, Salem, Tamil Nadu, India. E-mail: maniansenthil @yahoo.co.in

\section{References}

1. World malaria report 2011. Geneva: World Health Organization; 2011. http://www.who.int/malaria/world_malaria_report_2011/WMR2011_ noprofiles_lowres.pdf. [Last accessed on 2012 Oct 26].

2. Kochar DK, Das A, Kochar SK, Saxena V, Sirohi P, Garg S, et al. Severe Plasmodium vivax malaria: A report on serial cases from Bikaner in north western India. Am J Trop Med Hyg 2009;80:194-8.

3. Newton CRJC, Hien TT, White N. Neurological aspects of tropical disease: Cerebral malaria. J Neurol Neurosurg Psychiatry 2000;69:433-41.

4. Kamali NI, Huda MF, Srivastava VK. Falciparum malaria troubling neurosurgeons. J Postgrad Med 2012;58:61-2.
5. Seshadri P, Dev A, Viggeswarpu S, Sathyendra S, Peter J. Acute pancreatitis and subdural haematoma in a patient with severe falciparum malaria: Case report and review of literature Malar J 2008;7:97.

6. Chaudhary SC, Sonkar SK, Kumar V, Gupta A. Falciparum malaria presenting as subdural hematoma. J Assoc Physicians India 2011;59:325-6.

7. Huda MF, Kamali NI, Srivastava VK, Kaif M.Spontaneous acute subdural hematoma in malaria: A case report. J Vector Borne Dis 2011;48:247-8.

8. Jayavanth S, Park BC. Microrheologic dysfunctions in blood during malaria. Indian J Exp Biol 2007;45:111-20.

\begin{tabular}{|l|l|}
\hline \multicolumn{2}{|c|}{ Access this article online } \\
\hline Quick Response Code: & Website: \\
\hline & www.ruralneuropractice.com \\
\hline & \\
\hline & \\
\hline
\end{tabular}

